\title{
Injury Patterns at Isle Royale National Park: An Epidemiologic Review of Injuries and Illnesses Sustained in a Remote Environment
}

\author{
Kathleen D. Saxon, MD; Jenna M.B. White, MD; Mary M. Eddy, MD; Daniel L. Albertus, MD; \\ Benjamin S. Bassin, MD \\ From the Colorado Permanente Medical Group, Department of Emergency Medicine, Saint Joseph Hospital, Denver, CO (Dr Saxon); the \\ Department of Emergency Medicine, University of New Mexico, Albuquerque, NM (Dr White); and the Department of Emergency Medicine, \\ University of Michigan, Ann Arbor, MI (Drs Eddy, Albertus, and Bassin).
}

Objective.-Isle Royale National Park is a remote island in northern Lake Superior that attracts 16,000 visitors annually. The epidemiology of injuries and illnesses sustained by Isle Royale's visitors has not been previously studied. The purpose of this study is to examine these data and evaluate them for injury patterns.

Methods. - This is a retrospective observational study examining the epidemiology of injuries and illnesses sustained during the period from 2008 to 2012. Incident reports completed by park rangers were reviewed and the data sorted according to time of year, time of day, type of medical encounter, and whether the patient was stable, unstable, or required transport.

Results.-Two hundred and seventy patient care reports were obtained from the National Park Service. Sixty-four percent of encounters occurred in July and August, and most patients sought care in the afternoon. Care was provided by park rangers, the majority of whom were trained to the level of emergency medical technician. Fifty-eight percent of cases were trauma related, and $20 \%$ of all cases were evacuated.

Conclusions. - The majority of incidents were trauma related. The majority of the rangers on the island are trained to the level of emergency medical technician-B and appear to offer appropriate care to the island's many visitors, utilizing the National Park Service treatment protocols and comprehensive medical kits. In addition, access to advanced medical care is readily available by air and water evacuation.

Key words: epidemiology, Isle Royale National Park

\section{Introduction}

Isle Royale National Park, established in 1940, is a remote, beautiful island located in northern Lake Superior and is only accessible by seaplane or a 3-hour boat ride. The island, which is 45 miles long and 14 miles wide at its widest point, lies 56 miles from Copper Harbor, Michigan, and 15 miles from Canada. Approximately $99 \%$ of the park is designated as wilderness. ${ }^{1}$ The park is open to visitors from mid-April through the end of October. Isle Royale is the least visited national park in the continental United States and attracts approximately 16,000 visitors annually-less than the

Corresponding author: Kathleen Saxon, MD, Colorado Permanente Medical Group, Exempla St. Joseph Hospital, 1835 North Franklin Street, Denver, CO 80218 (e-mail: kdsaxon@gmail.com). number who visit Yellowstone in one day.,3 Visitors often backpack along the island's many rugged trails, or canoe or kayak and portage along the inland lakes and shores. In 1996, 54\% primarily hiked, $31 \%$ power boated, 9\% canoed, 3\% sailed, and 3\% kayaked. Backcountry visits are increasing, and Isle Royale ranks 10th among National Park Service (NPS) units at 50,000 nights spent in the backcountry per year. ${ }^{1}$ There are no cell phone towers, and electricity is limited to ranger stations on either end. The island is managed by the NPS, and NPS rangers provide emergency medical care to the visitors. Rangers are required to have basic medical training, and patients are transferred to Thunder Bay, Ontario, in Canada by plane or boat if a higher level of medical care is required.

The epidemiology of injuries and illnesses sustained by Isle Royale visitors has never been studied. The 
purpose of this study is to examine the data and evaluate them for injury patterns. While similar studies have evaluated the epidemiology of other national parks, ${ }^{4}$ the unique geography, climate, and remote location of Isle Royale exposes visitors to specific types of injuries, with significantly limited resources for care. The information may be used to determine the patterns, severity, and types of injuries most frequently encountered. Moreover, categorizing the timing (both time of day and season) of injury occurrence may help determine resources needed by the NPS, including staffing levels, level of medical training provided, medical kit contents, and whether the medical care currently available meets visitors' needs.

\section{Methods}

This is a retrospective observational study examining the epidemiology of injuries and illnesses sustained at Isle Royale National Park from 2008 to 2012. Patient care reports recorded by the NPS rangers at the time of service were examined. The data were obtained from the NPS and deidentified so the patient's name, age, and other identifiers were excluded before our review. The patient care report forms that are used for each incident allow documentation of appropriate information, including patient health information, date and time of day, chief complaint, history of present illness, and a timeline of patient care management. The charts were reviewed and data sorted according to time of year, time of day, type of medical encounter, and whether the patient was stable, unstable, or required transport. Unstable vitals were defined as heart rate greater than 100 or less than 60 beats/min, systolic blood pressure less than $100 \mathrm{~mm}$ $\mathrm{Hg}$, oxygen saturation less than $90 \%$, respiratory rate greater than 20 breaths/min, or temperature greater than $38.5^{\circ} \mathrm{C}$. The chief complaint, diagnosis, sex, medical history, and treatment plan for each incident were also recorded. The data were entered into a spreadsheet, and subsequent frequency analysis and visit severity to time of year were analyzed using Microsoft Excel (Microsoft, Redmond, WA). This study was determined to be exempt by our Institutional Review Board.

\section{Results}

Two hundred and seventy patient care reports were obtained from the NPS for the years 2008 to 2012, with an average of 57 reports per year. Sixty-four percent of encounters occurred in July and August, $27 \%$ occurred in May and June, and 9\% in September and October. Most visitors presented for care during the afternoon, while $31 \%$ presented in the morning, $25 \%$ in the evening, and $1 \%$ overnight. The 3 overnight cases included a patellar dislocation, syncope, and vomiting with right upper quadrant abdominal pain.

Of the patients who presented for care, 53\% were male, $37 \%$ were female, and $10 \%$ of the reports did not include the patient's sex. The majority of patients were previously healthy, whereas $38 \%$ listed at least 1 condition under medical history. Of the latter patients, $22 \%$ had prior orthopedic injuries, 9\% had hypertension, $4 \%$ had diabetes mellitus, $4 \%$ had a psychiatric diagnosis, $2 \%$ had a history of coronary artery disease, asthma, or hyperlipidemia, and fewer than $1 \%$ had atrial fibrillation, cancer, osteoporosis, seizures, or a history of stroke. Only 4 patients were taking an anticoagulant medication, including warfarin or clopidogrel. Nine percent of the reports did not list whether the patient had prior medical conditions.

Each patient was cared for by a park ranger, the majority of whom were trained to the level of emergency medical technician (EMT-B). Six patients were cared for by a wilderness first responder (WFR), and 1 was cared for by a physician.

Vital signs were not recorded on $45 \%$ of the patient care reports. Of the $55 \%$ obtained, $10 \%$ had vitals signs that were unstable. The sicker patients or those who were evacuated tended to have an increased amount of charting and serial vital signs documented. The majority of patients were treated and released, $20 \%$ were evacuated, and in 2 cases, the disposition was not listed on the report. Of patients evacuated, some left by boat to a waiting ground ambulance on the mainland or by air directly to a medical center. Others presented to care on the day they had been planning to leave the island and were evacuated by the scheduled ferry, although they had been planning to leave the island this way initially. Not all patients with unstable vital signs were evacuated; for example, 2 patients who presented with nausea, vomiting, and tachycardia were rehydrated and released.

The majority (58\%) of cases were trauma related, most commonly involving falls or soft-tissue injuries. Medical complaints comprised $42 \%$ of cases, most commonly involving skin infections and gastrointestinal complaints. The most common presenting chief complaints included ankle pain, lacerations, extremity pain, blisters, and lightheadedness. Several patients also presented with upper respiratory symptoms, skin infections, insect bites, hypothermia, eye complaints, and allergic reactions (Figure 1).

The most common treatment provided was wound care, which often included irrigation and a dressing. In some cases sterile strips were applied, but no suturing was performed. Other common treatments included rest, 
Incidence of Chief Complaints

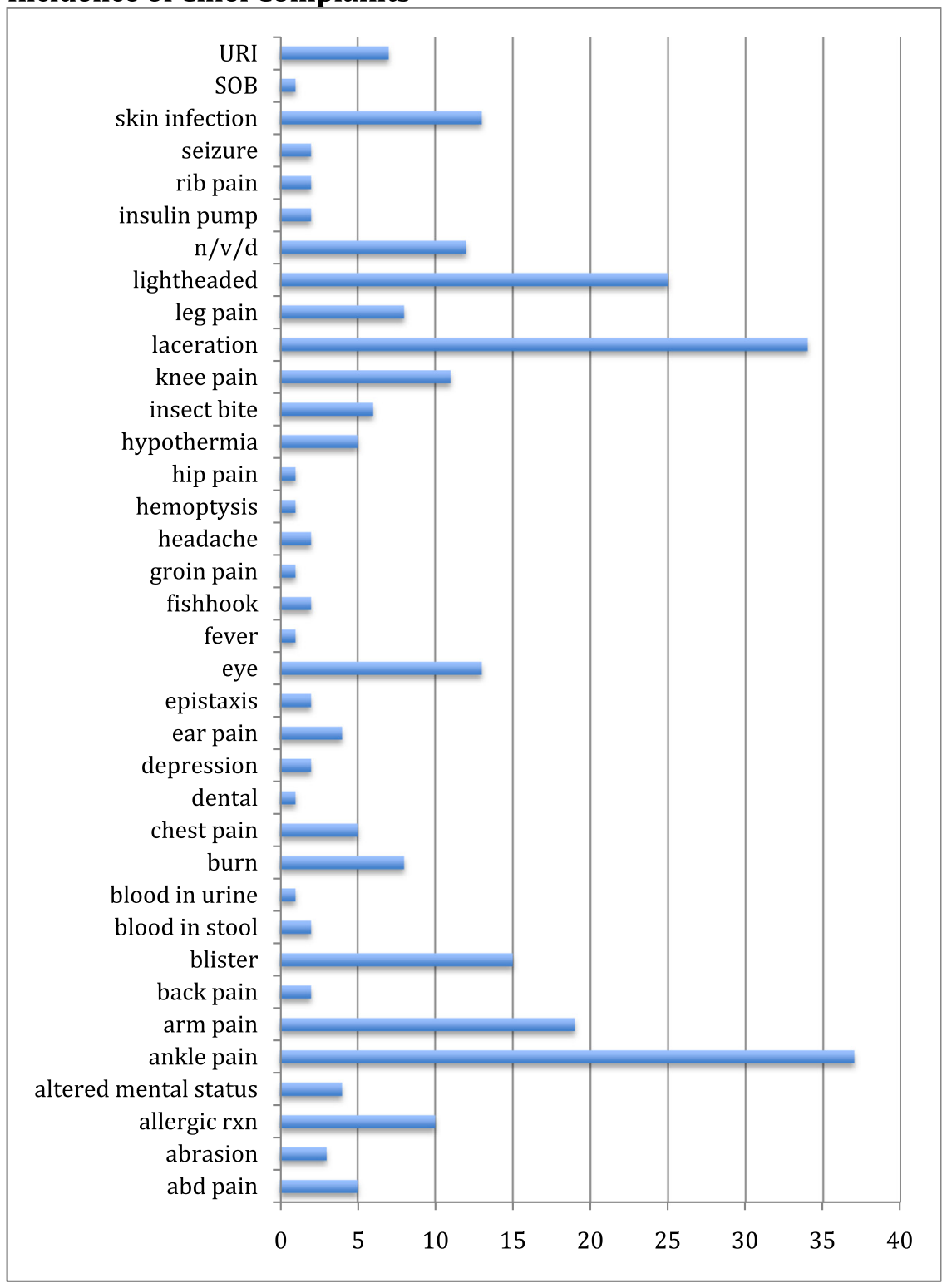

Number of Chief Complaints

Figure 1. Incidence of chief complaints from patients seeking care. URI, upper respiratory infection; SOB, shortness of breath; n/v/d, nausea, vomiting, diarrhea; rxn, reaction; abd, abdominal.

ice, compression, elevation ("RICE") for soft tissue injuries and ankle pain, as well as splinting and slings, ibuprofen administration, and oral hydration. Many patients were observed or offered reassurance regarding their presentation. Antibiotics were administered to 7 patients, most commonly for skin infections consistent with cellulitis. For the treatment of suspected allergic reactions, 4 patients received diphenhydramine, and 3 others required epinephrine. The 5 patients who were hypothermic were rewarmed with warm oral fluids. Twenty-five patients were evacuated, and 1 received oxygen. One patient left against medical advice (Figure 2). No fatalities were described.

\section{Discussion}

On Isle Royale National Park during the period from 2008 to 2012, the majority of visitor incidents were trauma related, and the most common complaints were ankle sprains, lacerations, and extremity pain. Those findings are consistent with the bedrock geologic features, and therefore rocky terrain, of the island and with 
Most common types of treatments

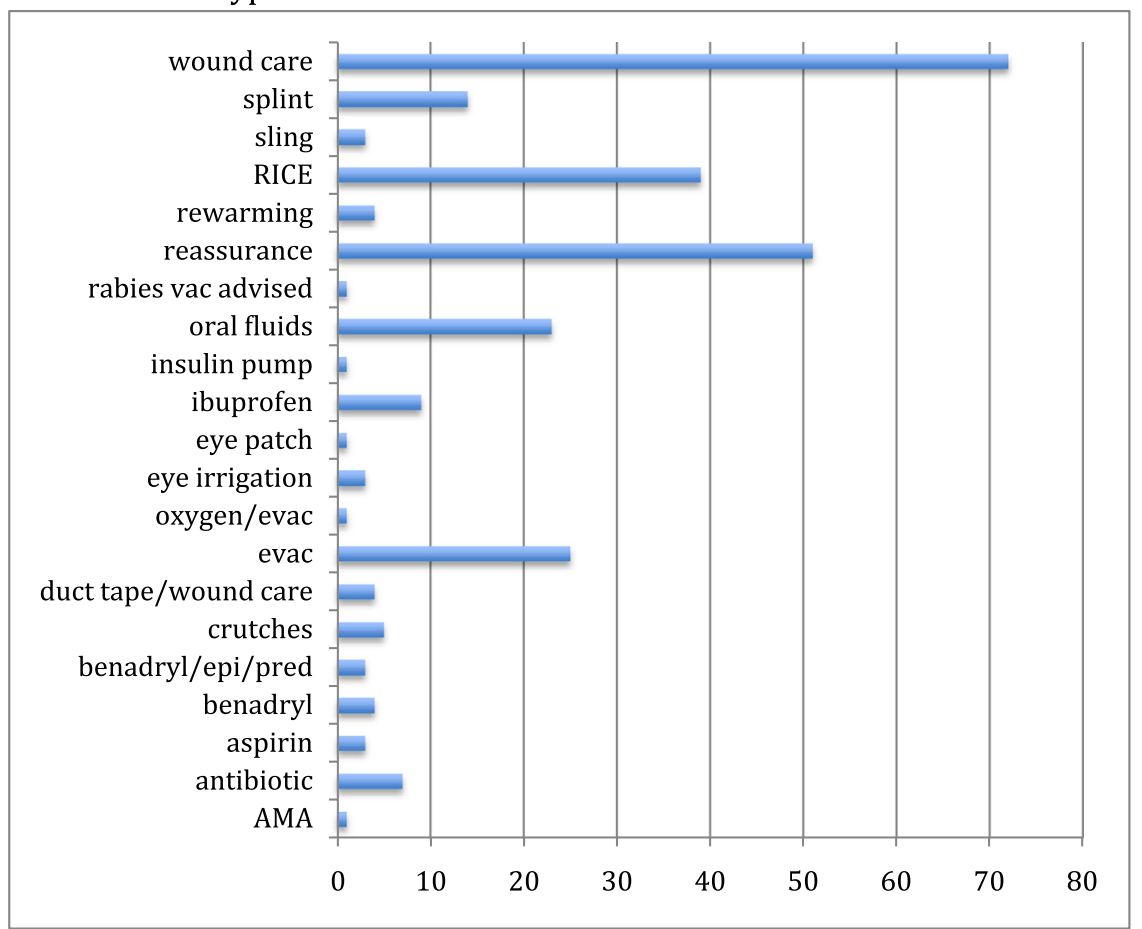

Number of individuals receiving this treatment

Figure 2. Most common types of treatments administered. RICE, rest, ice, compression, elevation; vac, vaccination; evac, evacuation; epi, epinephrine; pred, prednisone; AMA, against medical advice.

the majority of visitors being hikers, which places them at risk for musculoskeletal and soft tissue injuries. This finding is similar to search and rescue (SAR) statistics noted in a review of national parks, in which the most common activity resulting in a need for care was hiking. Also similarly, the majority of patients were male. ${ }^{4}$ Isle Royale was not among the top 10 NPS units with the highest occurrence of SAR operations, and that may be related to the low number of annual visitors and the terrain, as most SAR events occurred in a mountain, canyon, or river environment. ${ }^{4}$

Regarding the medical presentations, as in an emergency department or urgent care center in a large city, there was great variance in the types of complaints, which included lightheadedness, nausea, vomiting, and diarrhea, and also very specific problems, such as insulin pump malfunction.

The incidence of injuries and illnesses is most frequent during July and August, which are the most popular times to visit the island. The most usual time of day for presentation to care was the afternoon, which fits with the schedule of most backpackers or paddlers, who start out their daily trek in the morning and finish by late afternoon. A review of the NPS visitor use statistics showed a slightly greater likelihood to be injured in May and June relative to the number of visitors in those months: $21 \%$ of the annual visitors arrive in those months, and $27 \%$ of the incidents occur then. In July and August, $64 \%$ of incidents occur when $61 \%$ of visitors are present, and only $9 \%$ occur in September and October, when $11 \%$ of the visitors land on the island. ${ }^{5}$

The NPS operates under national protocols as documented in the NPS emergency medical services field manual, which contains an edition for basic and intermediate EMTs, as well as an edition for medical first responders. These protocols help park rangers determine whether to treat and release versus evacuate. However, one ranger said they frequently contact medical control at Aspirus Keweenaw Hospital in Michigan's Upper Peninsula and discuss the case with the emergency medicine physician on duty. If a case is more emergent or the disposition is obvious, the incident commander on site will make the decision to evacuate.

Although the most frequent treatment offered was wound care, the medical jump kit (see Table A1 in the Appendix) available to the medics on the island appears very comprehensive for the variety of illnesses and injuries that may be encountered, and there are several medications available as well (see Table A2 in the Appendix). The drug inventory includes medications 
authorized by national protocols as well as medications approved for local use by the park medical advisor. The medications are stored in Rock Harbor. Providers also carry personal kits with a smaller subset of the drug inventory, depending on their level of medical training. Forty-five percent of the patient care reports did not include patients' vitals signs; on review, these patients tended to have low acuity injuries and were treated and released, and the vital signs were likely stable.

\section{STUDY LIMITATIONS}

This study is limited by the data included on the patient care reports. To protect confidential patient health information, patients' names, dates of birth, and locations on the island were removed before we received the reports. Thus, our analysis could not include the age of the patients, and that also affected analysis of recorded vital signs-for example, 90/60 mm $\mathrm{Hg}$ may be an unstable blood pressure for an adult patient but may be normal for a pediatric patient. In addition, each form was handwritten by the provider, and at times was undecipherable. It was challenging to interpret the details on the charts of patients who required evacuation. Some of the providers documented "ambulance" as the means of patient transport. It is unclear whether the term "ambulance" applies to the NPS boat that transports patients across Lake Superior to the mainland or to a waiting ambulance on the mainland as there are no roads or motorized vehicles on the island.

\section{Conclusion}

In summary, between the years of 2008 and 2012, the majority of illnesses and injuries occurred during the most popular months for visiting the island, July and August, and the most frequent time of day for presentation was the afternoon. Of the patients who had vital signs recorded, most had stable vital signs. The chief complaint and treatment plan on the charts without vital signs recorded indicate that these patients were likely stable. Presentations due to minor trauma were most common. Medical complaints were variable, but frequently included gastrointestinal distress, lightheadedness, and skin infections. The majority of the rangers on the island are trained to the level of EMT-B, and they appear to offer appropriate care to the island's many visitors by utilizing the NPS treatment protocols and comprehensive medical kit. In addition, access to advanced medical care is readily available by air or water evacuation. However, the NPS patient care report form could benefit from an update.

\section{Appendix}

See Table A1 and A2.

\section{References}

1. Farrell TA, Marion JL. Camping impact management at Isle Royale National Park: an evaluation of visitor activity containment policies from the perspective of social conditions. USDA Forest Serv Proc. 2000;5:110-114.

2. Isle Royale National Park. History and culture; management. Available at: http://www.nps.gov/isro/index.htm. Accessed August 11, 2013.

3. Isle Royale backpacking. A guide for backpacking on Isle Royale. Available at: isleroyalebackpack.com. Accessed August 11, 2013.

4. Heggie T, Amundson M. Dead men walking: search and rescue in US national parks. Wilderness Environ Med. 2009;20:244-249.

5. National park user statistics. Annual park recreation visitation and monthly public use. Available at: https://irma.nps. gov/stats/reports/park. Accessed January 25, 2014. 
Table A1. Medical jump kit contents

\begin{tabular}{|c|c|}
\hline Item & Number \\
\hline Epinephrine kit & 1 \\
\hline Acetaminophen $325 \mathrm{mg}$ & 4 \\
\hline Ibuprofen $200 \mathrm{mg}$ & 4 \\
\hline Motion sickness $50 \mathrm{mg}$ & 4 \\
\hline Aspirin $325 \mathrm{mg}$ & 4 \\
\hline Diphenhydramine $25 \mathrm{mg}$ & 6 \\
\hline Glucose-15 $37 \mathrm{~g}$ tube & 2 \\
\hline Antacid $420 \mathrm{mg}$ & 4 \\
\hline Nitroglycerin $0.4 \mathrm{mg}$ & 25 \\
\hline Antibiotic cream & 4 \\
\hline Burn gel & 4 \\
\hline Activated charcoal & 1 \\
\hline Eye irrigation & 1 \\
\hline Kendrick traction device & 1 \\
\hline Backboard kit & 1 \\
\hline AED kit & 1 \\
\hline Oxygen kit & 1 \\
\hline Emergency blanket & 2 \\
\hline EMS pocket guide (BLS) & 1 \\
\hline Patient care report & 5 \\
\hline $\begin{array}{l}\text { PPE (gloves, pocket mask, } \\
\text { sharps container, etc) }\end{array}$ & Multiple \\
\hline Blood pressure cuff & 1 \\
\hline Stethoscope & 1 \\
\hline Glucometer & 1 \\
\hline Thermometer & 1 \\
\hline Eye examination light & 1 \\
\hline Tongue depressor & 1 \\
\hline Bandages & Multiple \\
\hline Dressings & Multiple \\
\hline Closures (butterfly, Steri-strip) & Multiple \\
\hline Tourniquet & 1 \\
\hline Hot packs & 2 \\
\hline Cold packs & 2 \\
\hline Emergency blanket & 2 \\
\hline $\begin{array}{l}\text { Trauma tools (shears, forceps, } \\
\text { tweezers, fish hook and splinter removal kits) }\end{array}$ & Multiple \\
\hline
\end{tabular}

AED, automated external defibrillator; EMS, emergency medical services; BLS, basic life support; PPE, personal protective equipment.
Table A2. Drug inventory

\begin{tabular}{|c|c|}
\hline Drug & Form \\
\hline Acetaminophen $325 \mathrm{mg}$ & Tablets \\
\hline \multicolumn{2}{|l|}{ Activated charcoal } \\
\hline Albuterol INH & MDI \\
\hline \multicolumn{2}{|l|}{ Amiodarone $150 \mathrm{mg}$} \\
\hline ASA $81 \mathrm{mg}$ & Tablets \\
\hline Atropine & Syringe \\
\hline Bacitracin ointment & Packets \\
\hline Cefazolin $1 \mathrm{~g} / 10 \mathrm{~mL}$ & Vial \\
\hline Ceftriaxone $1 \mathrm{~g} / 10 \mathrm{~mL}$ & Vial \\
\hline Cephalexin $250 \mathrm{mg}$ & Capsules \\
\hline Ciprofloxacin $500 \mathrm{mg}$ & Tablets \\
\hline Glucose paste & $15 \mathrm{~g}$ tube \\
\hline Dextrose $50 \%$ abbj & Preload \\
\hline Diphenhydramine $25 \mathrm{mg}$ & Tablets \\
\hline Diphenhydramine $50 \mathrm{mg} / 1 \mathrm{~mL}$ & Preload \\
\hline Epinephrine 1:1000 & Vial \\
\hline Epinephrine 1:10000 & Syringe \\
\hline Erythromycin ophthalmic ointment & Solution \\
\hline Fentanyl $250 \mu \mathrm{g} / 5 \mathrm{~mL}$ & Vial \\
\hline Furosemide $100 \mathrm{mg} / 10 \mathrm{~mL}$ & Preload \\
\hline \multicolumn{2}{|l|}{ Glucagon kit } \\
\hline Halcinonide cream & Cream \\
\hline Haloperidol $5 \mathrm{mg} / \mathrm{mL}$ & Injectable \\
\hline Hydrocodone/acetaminophen 5/325 mg & Tablets \\
\hline Hydromorphone $1 \mathrm{mg} / \mathrm{mL}$ & Vial \\
\hline Ibuprofen $200 \mathrm{mg}$ & Tablets \\
\hline Insulin regular & Vial \\
\hline Atrovent INH & MDI \\
\hline Ketamine $500 \mathrm{mg} / 10 \mathrm{~mL}$ & Injectable \\
\hline \multicolumn{2}{|l|}{ Lidocaine $1 \%$} \\
\hline Loperamide $\mathrm{HCl} 2 \mathrm{mg}$ & Capsules \\
\hline Magnesium sulfate $50 \%$ & Vial \\
\hline Midazolam $10 \mathrm{mg} / 2 \mathrm{~mL}$ & Vial \\
\hline Morphine sulfate $10 \mathrm{mg} / 1 \mathrm{~mL}$ & Syringe \\
\hline Naloxone $2 \mathrm{mg} / 2 \mathrm{~mL}$ & Preload \\
\hline Neomycin/polymixin B & Solution \\
\hline Nitroglycerin & SL or tablets \\
\hline Normal saline $0.9 \% 1000 \mathrm{~mL}$ & Bags \\
\hline Ondansetron $4 \mathrm{mg}$ & Tablets \\
\hline Oxytocin & Ampules \\
\hline Silver sulfadiazine $1 \%$ & Cream \\
\hline Sodium bicarbonate $50 \mathrm{mEq}$ & Preload \\
\hline Sulfamethoxazole/trimethoprim & Tablets \\
\hline Tetracaine $\mathrm{HCl} 0.5 \%$ & $15 \mathrm{~mL}$ bottle \\
\hline Wound wash & Spray \\
\hline
\end{tabular}

INH, inhalation; MDI, metered-dose inhaler; ASA, acetylsalicylic acid; SL, sublingual. 